\title{
The Role of Forensic Dentistry for Identification of a Criminal Sexual Assault: A Casework Report
}

\section{Cristiana Palmela Pereira ${ }^{1,3,4 *}$ and Jorge Costa Santos ${ }^{2,3}$}

${ }^{1}$ Auxiliary Professor from Faculty from University of Lisbon, Scientific Consultant of Forensic Dentistry, South Branch of Portuguese National Institute of Legal Medicine and Forensic Sciences, PhD in Legal Medicine and Forensic Sciences, Portugal

${ }^{2}$ Auxiliary Professor from Medical Faculty from University of Lisbon, Director of the Forensic Pathology and Forensic Clinical Departments from the South Branch at the Portuguese National Institute of Legal Medicine and Forensic Sciences, PhD in Legal Medicine and Forensic Sciences, Portugal ${ }^{3}$ Investigators from CENCIFOR, Centre of Forensic Studies, Portugal

${ }^{4}$ Integrate Research from the Research Centre of Statistics and Applications of the University of Lisbon (CEAUL) Portugal

\begin{abstract}
The identification of an individual from dental traces collected at the crime scene is one of the objectives of the criminal investigation. When, at the crime scene, objects are found with tooth marks, the intervention of Forensic Dentistry may represent the only way to obtain positive identification of the author's bite mark. The forensic analysis of a bite mark consists of detection, recognition, description and comparison of bite marks on either individuals or inanimate objects. In this medico-legal casework, a sexual assault, the victim of the crime presented to the forensic examination had a mark on her left arm consistent with a bite mark, probably from the aggressor during the crime perpetration. The protocol followed in this medico-legal casework study is a scientific analysis of the facts which when presented in the court will be defendable under ruthless cross-examination. The pattern association of dental features in this sexual abuse case demonstrated a degree of concordance present between the tooth marks in the victim's body and the suspect's dentition.
\end{abstract}

Keywords: Forensic dentistry; Individual positive identification; Sexual abuse

\section{Introduction}

The identification of an individual from dental traces collected at the crime scene is one of the objectives of the criminal investigation. When, at the crime scene, objects are found with tooth marks, the intervention of Forensic Dentistry may represent the only way to obtain positive identification of the author's bite mark [1]. The forensic analysis of a bite mark consists of detection, recognition, description and comparison of bite marks on either individuals or inanimate objects. The forensic investigation involves several steps. The first question that arises is whether this injury is a bite mark or may have been caused by another factor. The second question, after establishing the injury as a bite mark and human, is whether it was caused by an adult or a child. The last question in the process of research identification, after recognizing trauma as a bite mark, if it is comparable to exclude or include - establishing the causal link with the subject, establish the identity of the perpetrator in a bite mark case [2].

\section{Casework}

In this medico-legal casework, a sexual assault, the victim of the crime presented to examination had a mark on her left arm consistent with a bite mark (Figure 1), probably from the aggressor during the crime perpetration. However, when she was presented for the forensic examination by the Portuguese Criminal Police the skin was already washed since the sexual assault and the bite was inflicted more than 72 hours. The Portuguese Criminal Police requested to South Branch of National Portuguese Institute of Legal Medicine and Forensic Sciences, IP, an expert forensic odontologist examination from the victim only with the propose of the examination of physical evidence. The objectives were: 1) the reconstruction of the morphologic profile of the bite mark in the victim; 2) the possible identification of the author of the bite mark-inclusion or exclusion of the suspect of the alleged perpetrator. Each stage of the analysis adds to the confirmation (or rejection) of concordance between the dental features present on the arm of the victim and the dentition of the suspect.

\section{Materials and Methods}

In this casework, we used the guidelines of American Board of Forensic Odontology (ABFO) for the reconstruction and analysis of morphological profile of the bite marks on human skin and collection

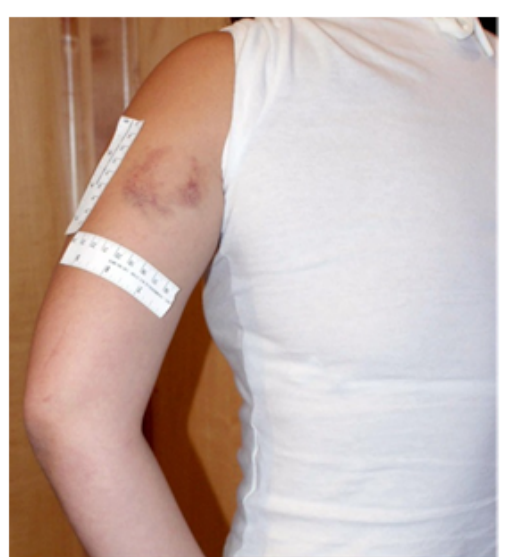

Figure 1: A female victim of sexual assault had an injury on the skin of the posterior area from the left arm confirmed in the initial forensic identification as a human bite mark.

*Corresponding author: Cristiana Palmela Pereira, Auxiliary Professor from Faculty from University of Lisbon, Portugal, Tel: 351217967624; E-mail: cristiana.pereira@fmd.ul.pt.

Received November 07, 2014; Accepted December 30, 2014; Published January 10,2015

Citation: Pereira CP, Santos JC (2015) The Role of Forensic Dentistry for Identification of a Criminal Sexual Assault: A Casework Report. J Civil Legal Sci 4 138. doi:10.4172/2169-0170.1000138

Copyright: (c) 2015 Pereira CP, et al. This is an open-access article distributed under the terms of the Creative Commons Attribution License, which permits unrestricted use, distribution, and reproduction in any medium, provided the original author and source are credited. 
of dental morphological profile of the alleged perpetrator of the bite mark, to establish the identity or exclusion with a high degree of certainty [3].

\section{Examination of the Victim and the Human Bite Mark}

A female victim of sexual assault had an injury on the skin of the posterior area from the left arm confirmed in the initial forensic identification as a human bite mark. The appearance of the bite mark was a single diffused contusion area with a double-arched with some dental features in the lower arch from the bite mark (Figure 2). After the macroscopic examination for the confirmation of the bite mark it was taken the photographs under high resolution and colour balance, and with filters at a wavelength of 415 to $450 \mathrm{~nm}$ without and with scale $\mathrm{ABFO} n .{ }^{\circ} 2$ in the same plane and adjacent to the bite mark to avoid distortion [4].

After was collected the impression of the bite mark area (Figure 3) with two different consistency of a silicone material, the light consistency and the putty consistency, the last one to avoid the deformation of the light elastomeric consistency material that gives the definition of the dental details of the bite mark [5].

The analysis of the bite mark pattern (Figure 4) showed in the lower arch four individualized marks consistent with three incisal edges from teeth 32, 31 and 4;1 and from the canine cusped (tooth 33). Between the teeth 31 and 41 we verified the existence of a diastema with severe bruising due to traumatic force caused by a blunt instrument, but not a tooth; and we observed other diastema between the teeth 32 and 33 . The upper contusion was compatible with the impression of the upper lip of the aggressor.

Dental features individualized from the pattern of the bite mark: yellow circles form the left side to right side of the image: teeth $41,31,32$

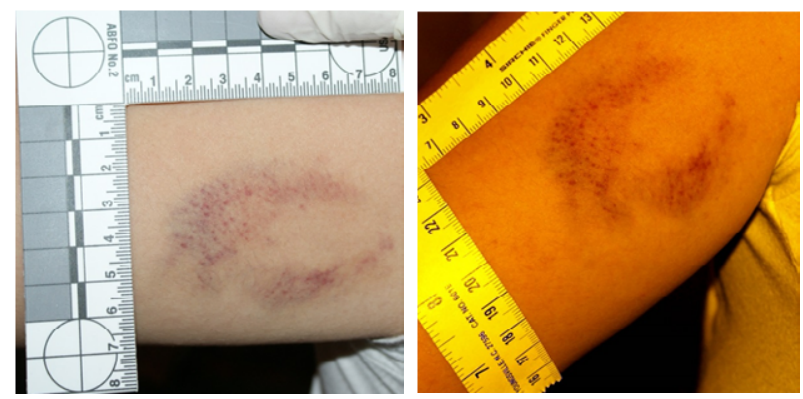

Figure 2: Photograph of the bite mark showed a single diffused contusion area with a double-arched with some dental features in the lower arch from the bite mark.
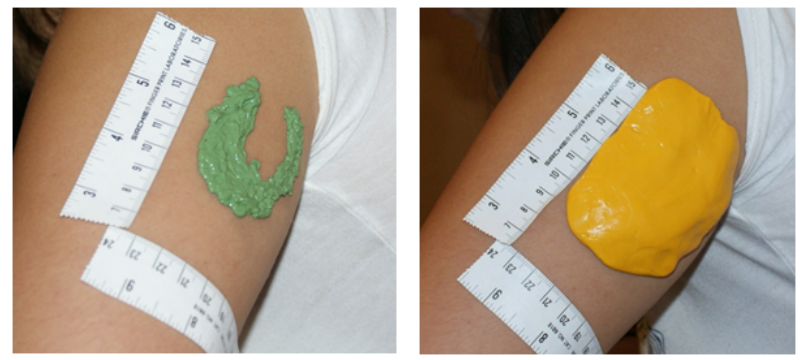

Figure 3: The impression of the bite mark area with two different consistency of a silicone material.

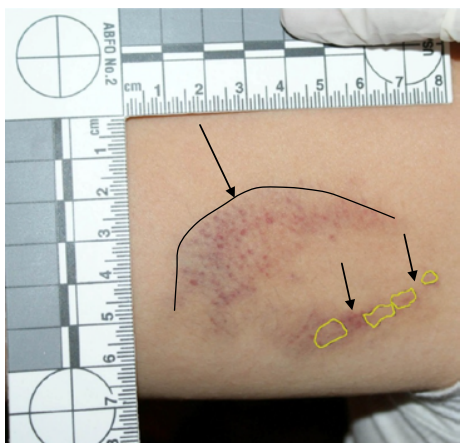

Figure 4: Dental features individualized from the pattern of the bite mark yellow circles form the left side to right side of the image: teeth 41,31 , 32 and 33.
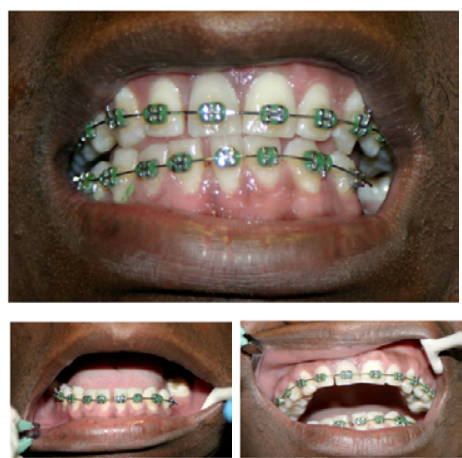

Figure 5: Intraoral photographs from the suspected.

and 33. The arrow between teeth 41 and 31 indicated the diastema and the contusion area. The arrow between teeth 32 and 33 indicated the other diastema. The upper arrow indicated the generalized contusion compatible with a upper lip (Figure 4).

\section{Examination of the Suspect}

Extra oral examination included the examination of hard and soft tissues factors, TMJ status and facial asymmetry muscle zone. Maximum inter incisal opening, deviations in opening/closing the jaws, occlusal disharmonies should also be well photographed [6]. Intra oral examination included the examination of tongue for size and function, periodontal examination and condition of teeth were noted [6] (Figure 5). Two impressions of each arch with ADA (American Dental Association) specified material is followed by obtaining dental casts with type II stone [5].

The analysis of the dental features of the suspect showed the presence of fixed orthodontic treatment with brackets and steel wire. We observed a diastema between the teeth 31 and 41 with the presence of steel wire; and also a diastema between the teeth 32 and 33 (Figure 5). The type of the lips was full.

\section{Results and Discussion}

After reconstruction of the pattern of bite mark, the identification or exclusion from the suspected is based on a comparative scientific method, which must take into account the chain of custody and all the useful information related to this case study. 

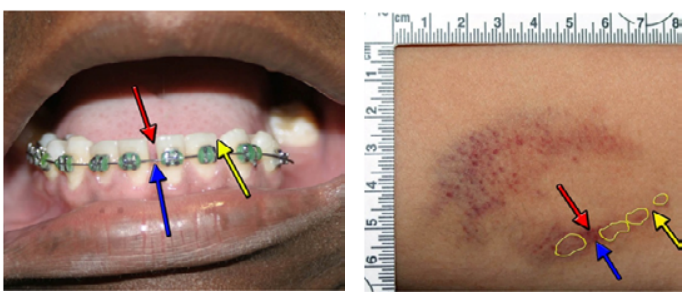

Figure 6: Left side the intraoral photograph from the suspected with the dental features compatible with the right side photograph from the bite mark from the victim.

\section{Bite Mark Analysis and Identification}

The exact identification of a living person using individual traits and characteristics of the teeth and jaws is the basis of forensic science. The bite marks left on a person may be used to identify the perpetrator. Bite mark identification is based on the individuality of a dentition, which is used to match a bite mark to a suspected person [7]. One can exactly match the bite marks to the accused biter's dentition. The most important step in bite mark analysis is to recognize a patterned injury as a human bite mark followed by pattern analysis of the bite mark which provide the individual information about the suspect or an offender and relate the person who is involved in the crime. It is important to have individual characteristics in the bite mark to identify the perpetrator [8]. In this forensic casework the individual dental traits were: the presence of the diastema between the teeth 33 and 32 and between 31 and 41 ; the presence of the steel wire between the mesial surfaces of the tooth 31 and the tooth 41 . The dental pattern from the suspected was compatible with the injury pattern observed in the skin of the victim (Figure 6). Additionally the type of the lips of the suspected was compatible with the impression of the upper lip observed in the skin of the victim.

Left side the intraoral photograph from the suspected with the dental features compatible with the right side photograph from the bite mark from the victim: the red arrow show the diastema between the teeth 41 and 31 compatible between the two dental patterns (suspected

Citation: Pereira CP, Santos JC (2015) The Role of Forensic Dentistry for Identification of a Criminal Sexual Assault: A Casework Report. J Civil Legal Sci 4: 138. doi:10.4172/2169-0170.1000138 and bite mark); the blue arrow show the steel wire in the suspected compatible with the contusion area in the victim with direct relation with the contusion instrument of the suspected; the yellow arrow show the diastema between the teeth 32 and 33 compatible between the two dental patterns (suspect and bite mark) (Figure 6).

\section{Conclusion}

Bite mark analysis is an important aspect of forensic dentistry that is invaluable in solving crimes and in identification of persons involved in criminal activities. The protocol followed in this medico-legal casework is a scientific analysis of the facts which when presented in the court will be defendable under ruthless cross-examination. The pattern association of dental features in this sexual assault case demonstrated a degree of concordance present between the tooth marks in the victim's body and the suspect's dentition.

\section{Acknowledgment}

FTC-PEst-OE/MAT/UI0006/2014.

\section{References}

1. Page M, Taylor J, Blenkin M (2012) Reality bites A ten-year retrospective analysis of bitemark casework in Australia. Forensic Science International 216 82-87.

2. Sweet D (1995) Human Bite marks: Examination recovery and analysis. In Bowers CM, Bell G, editors. Manual of Forensic Odontology. Ontario: Manticore.

3. ABFO (2010) American Board of Forensic Odontology - Diplomates Reference Manual.

4. Rawson RD, Vale GL, Herschaft EE (1986) Analysis of Photographic Distortion in Bite Marks: A Report of the Bite Mark Guidelines Committee. Journal of Forensic Sciences 31: 1261-1268.

5. Pereira C, Santos JC, Solheim T (2009) Evidence Collection of a Tooth Mark in a Crime Scene: Importance of the Dental Materials in Forensic Dentistry. Revista Portuguesa Estomatologia Medicina Dentária Cirurgia Maxilofacial 50 141-144.

6. Pretty IA (2008) Forensic Dentistry: 2. Bite marks and Bite Injuries. Dental Update 35: 48-50.

7. Bush MA, Miller RG, Bush PJ (2009) Biomechanical factors in human dermal bite marks in a cadaver model. Journal of Forensic Sciences 54: 167-176.

8. MacDonald DG (1974) Bite mark recognition and interpretation. Journal of Forensic Science Society 14: 229-233.
Submit your next manuscript and get advantages of OMICS Group submissions

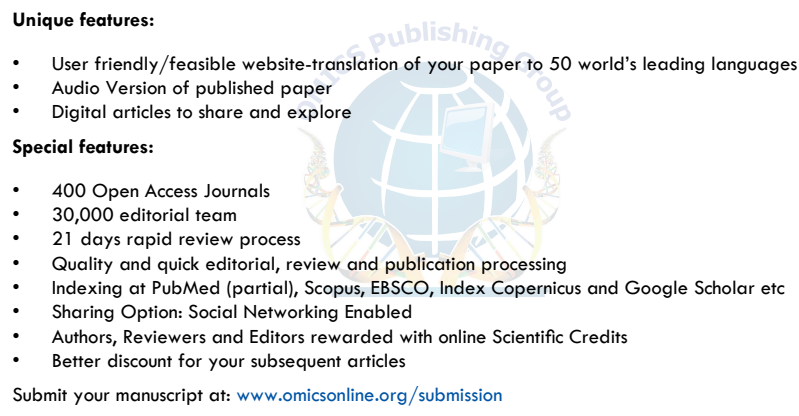

